\title{
DEMAND FORECAST, UP-TO-DATE MODELS, AND SUGGESTIONS FOR IMPROVEMENT AN EXAMPLE OF A BUSINESS
}

\author{
*Batuhan KOCAOGLU \\ *A. Zafer ACAR \\ *Behlül YILMAZ \\ *Okan University
}

\begin{abstract}
Businesses must use their resources optimum in order to minimize their costs. Thus, it is important to prepare the strategic plans made as the closest to the truth. Furthermore, in order their works to be sustainable, the companies should plan the future not the present; must take necessary measures to manage the cost of the inventory, labor, time, and financial resources in the best way and to avoid wastage. Demand forecasting systems, besides providing the company keeping up with changing market conditions easily, provides convenience to the company in operational applications with its strategic and managerial level plans. As the demand forecasting performance goes down, the rate of fulfillment the demands of the customer on time goes down. As a result, the companies head for accelerated services with quickly obtainable results, and other costly actions.

The starting point of short-and long-term plan is the forecast demand. Also, as the deviations in long-term plans are high, the determination of the control frequency and methods of the plans are very significant for a successful demand forecasting system. No matter how successful strategic plannings are done, the mistakes in the practice can drag all of the plans towards failure. Therefore, in our study, numerical and non-numerical of demand forecast models will be referred, and there will be comments about a demand forecasts method in a business with the case analysis method and suggestions for improvement.
\end{abstract}

Keywords: Demand forecasting, ERP, material planning, production planning, demand planning, supply chain management.

\section{INTRODUCTION}

Today, predicting the future position has gained a great importance both from the point of the companies and national/international economies. Demand forecasting systems, besides providing the company keeping up with changing market conditions easily, provide convenience to the company in operational applications with its strategic and managerial level plans. Forecasting applications developed by contemporary methods, have gained a wide strength especially in today's business economy. With this scope, monitoring the change, and being able to understand the market expectations correctly and modeling; are the bases of developing a successful mechanism in the future. In today's economies, in which micro and macro variables exist, the need of the sectors for applied scientific method is much more than the past.

As Ziff (1971) argued that "'Human being is an accustomed creature, if you want to see what he is going to do, ask him what he did yesterday"', forecasting is an ordeal. However, many researches show that future is the reflection of the past. So, while making forecast about the future, we must examine the past.

In today's complex world, administrators are faced with planning and decision-making process of whose results are vital for businesses. Within this scope, forecasting has become a must, not an ordinary study. Forecasting sales and the determination the amount of the product which will be on sale are the first things to start working on while planning. For that reason, the demand forecasting of the product that will be produced should be done. The planning cannot be regarded without determining the demand of the product to be produced. Because the raw materials, packing, catalogue, semi-manufacturing, machine, manpower and investment requirements will be determined according to these plannings. The demand, with the assumption that nothing has changed, show the amount of the product from each level of price, that the customers want to buy, in a time/unit chart. Roughly, demand is the desire measure of the people to buy a product or a product which will be produced. Forecasting 
can be defined as the determination of the data that belongs to a variable in the past periods and how will it be in the future.

Demand forecasting is the function to foresee the amount of goods and services the customers will demand in the future. Forecasting forms the basis of production plans and the business. Demand forecasting such as which product to produce, the amount the consumer demand from these product, the most probable dates on which these demands will actualize are determined in advance. In demand forecasts, numerical and non-numerical applications are used. Non-numeric demand forecasting is based on the information and experience of the forecaster. And, numerical methods of demand forecasting compromise of techniques based on cause and effect relationships and methods based on time series analysis.

In this context, the aim of our study is to shed light on how to choose and improve accurate prediction model. Basically, besides being on forecasting model, our study will focus on the commission of Sales and Operation Planning (S\&OP) in which transparency and cooperation is in the forefront, and will be based on the evaluation of the results in a production enterprise.

\section{DEMAND FORECAST}

Demand forecast is used in wide range from the inventory management, shipping, distribution, reclamation, repair and maintenance to the coordination of suppliers and operations of many works (Fildes et al., 2006; Küsters et al., 2006). When it used effectively, it will help supplier chains adoptions of companies or to the changeable market conditions (Fildes and Beard, 1992; Gardner, 1990; Wacker and Lummus, 2002). When performance decreases, companies head for services -which is accelerated and easily achieved to the resultand for upscale actions and fundamental services (Armstrong, 1988; Winklhoferet et al., 1996).

Possible future variants of a phenomenon or object, maybe even variant solutions of ways leading to future situations are formulated. The forecasting creates a basis for planning company processes (Johnson, 2009). It enables managers to plan future needs and consequently make rational decisions. Forecasting is a continuous process that requires product managers to think about markets and understand those (Haines, 2008).

\section{General concepts related to demand forecasting}

Demand forecast is an analysis and regulation process of information which makes possible forecasts of future sales. Order quantity, demand of the customer and date of accruing are interpreted with demand assumption.

Development of demand forecast is a multi-stage process which includes indication of processor demand and indication of formal demand (Kress and Snyder, 1994). After evaluating and determining the interior and exterior effect upon production demand, processor demands of production are improved. Many companies indicate their marketing strategy according to these forecasts. At the end of the process, efficiency of the forecast is followed. It is important to observe consistency of result and taking precaution in accordance with the situation. Qualitative and quantitative techniques are important during decision process. Decision makers primarily choose the most appropriate forecast techniques for the nature of the problem. Estimation operation should have mutual functions with estimation type, accessible source of information and current forecast techniques (Monks, 1987).

Demand planning represents a set of methodologies and information technologies for the use of demand forecasts in the process of planning. The aim is to accelerate the flow of raw materials, materials and services beginning with the suppliers through transforming to products in the company and to their distribution to their final consumers. The demand planning process is done to help the business understand profit potential. Indirectly it sets the stage for capacity, financing, and stakeholder confidence (Sheldon, 2006). The implementation of the demand planning enables to determine the closest possible forecast to the planning horizon and decide the volume of production, stock and sources capacity distribution among particular products to maximize the profits of the whole company.

Forecast techniques are used during decision-making process of enterprise. Enterprises should be aware of factors such as time interval permanent -Long term results of decisions, reaching data-set, quantity of obtained data, cost, margin of error and qualification of decision makers. (Schroeder, 1989; Klassen and Flores, 2001).

Demand forecast is used by the whole functions of the enterprise that undergoes changes on its process. Depending upon strategical changes, business plan is determined; depending upon business plan, budget is 
determined; depending upon budget and business plan, functional targets and actions are determined. Both strategical -administrative - plans and support process must be aware of demand forecast, while generating their own plans and targets. Within this scope, some questions to specify the target of the function will be as following; If we increase the ads budget by $\% 10$, how will the sales be affected?(Marketing \& Sales). What will the new products released be within the next two years? (R\&D department, regularity affairs, Marketing), what will the growth rate be in next two years? Will we need new employee and/or organizational settlement? (Human Resources).

\section{Forecasting methods}

Forecast methods are classified as objective/subjective, statistical/judicial, time series/regression/judicial procedure, qualitative time series/causal patterns and qualitative/quantitative. In this work, demand forecast methods are analyzed as qualitative and quantitative. Quantitative method is a combination of extrapolation of previous studies and it consists in statistical method (Wilson and Keating, 2001).

Qualitative forecast technique requires a person's idea and decisions collections which are related to future and present situation (Monks, 1987). The opinions of the experts are handled with subjective factors and experiences (Render and Stair, 2000). Qualitative techniques can be used during the inefficiency of numeric data and uncertain or changeable data excessiveness. Qualitative forecast technique's inputs can be obtained from many sources. These sources can be clients, sales person, manager, craft or experts apart from companies (Stevenson, 1989).

Qualitative technique, which is used in decision making process, can be classified as Delphi technique, market resources, expert groups' opinion and sales force mixed (Zoghby, 2002). Despite handling with abstract and subjective experiences, qualitative techniques are generally concluded with low prediction performances due to bias and tendency.

As good as qualitative techniques -experts attitude and opinions- quantitative data analysis and many statistical method results- 'quantitative' forecasting techniques is used for companies. To use 'quantitative' method, we have to reach quantitative data. Numerical data, which is used in quantitative techniques, take the advantage of barcode technology, point of sale (POS) data and clients. Furthermore it utilizes the information technology to obtain precise information. For instance, information about customers can be saved into the database with customer relationship management (CRM) software. This information is shared with other suppliers via enterprise resource planning (ERP) systems (Sanders and Manrodt, 2003). Today's technology enables us to obtain information such as momentarily cash register information, promotion, quantity and name. In this context, it is possible to indicate customer loyalty -with card that is designed with customer loyalty programs - and product portfolio which is bought by customer. These kinds of data are evaluated within the frame of data mining.

Fundamental assumption of method is permanency of distinctive trends. Even if this assumption is partly correct for the near future, as long as forecast horizon broaden, accuracy of quantitative methods is decreasing. As long as tendency- is formed by forecast - changes, their usage opportunity is also decreasing. To apply quantitative methods, three conditions should be completed (Colin, 1997):

1. Information about past

2. Rendering information as a data

3. Continuation of previous tendency in the future

\section{Points to consider in efficient demand forecast}

Rapidly developing information technology is mostly an advantage for both sides. That makes information sharing inevitable between supplier and retailer (Maltz and Srivastava, 1997). For that reason demand forecast is the basic of production planning. A planning, which is made without thinking about demand, is not a real planning. Purchasing transaction will be more efficient by demand forecast. Many companies, who serve in the consumer market, make a forecast. When the factor, that affects the demand, is permanent and methodical, forecast will be prophetic and exact. Especially in the small scale enterprises-whose list of goods are low and limited. These estimates never mislead the owner (Kerkkanen et al., 2009). However, as long as enterprise and list of goods are growing, different tools and methods are used in demand forecast. 
Customer needs are variable and it differs depending on geographic, demographic, psychological, sociocultural and its profits (Kayhan et al., 2005). Determining the customer needs and their behavior towards purchasing is the key point of forecast. Elucidator information about customer need and purchasing is buried in the past. For that reason, analyze of time series and stochastic models are used for the resolution of problems. Factors which affect the sale should be taken into consideration. Demand analysis is based on demographic, economic and psychological models and theories. That's why human dynamics are the factors which should be taken into consideration.

It is really difficult to make forecast without having information about previous sales, supplies, operation time, cost record and sales price. On the other hand, forecaster should consider his aim and information that he is supposed to collect seriously. Defective or more detailed information affects the result negatively and it increases the amount of research. Additionally, there is a close link between use of demand research results and length of period. Use of daily forecasts for the monthly periods can give deceptive results. Changes on daily value are vanished in monthly period.

Last, but not least, qualifications of gathered information's such as uncertainty and accuracy are the factors which should be taken into consideration. Same criterion should be applied while doing defect measurement. Since forecasting has become more important than measurement of daily application (Mentzer and Moon, 2009). One of the most important conditions of working with low stock is forecasting of sales. Thus, planning and determining of safety stock gets easy, and stocks daily value is getting decreasing. Key performance indicator (KPI) leads sustainable growth with increasing the investment and decreasing the risk level of the company. Increase in the forecast accuracy decreases overstock, disinvestment and the transfer number while it is increasing customer service levels and delivery speed.

\section{DEMAND FORECAST AND S\&OP EFFECTS}

S\&OP (Figure 1) is a process that should adapt constantly and focus on the whole functions of organization. S\&OP is an integrated business management process, which was formed by Oliver Wight in 1980. This operation method can be explained bottom to top and top to bottom transmitting forecast. We can explain it as a work whose primary objective is the way of work that formed demand and supply by means predicated on reconciliation. Process is started by supply chain members to talk about actions that satisfy customer demand and campaign such as operation, marketing, new plans about sales and finance. In the direction of the decision that is taken by executives, mechanism works downwards and the whole operation members make an analysis for their own part. This analysis can be explained as a demand sharing for the sale, production planning, capacity plans efficiency controls, number of employees and shift plans for the production department, resource supply controls for the finance department (Grim 


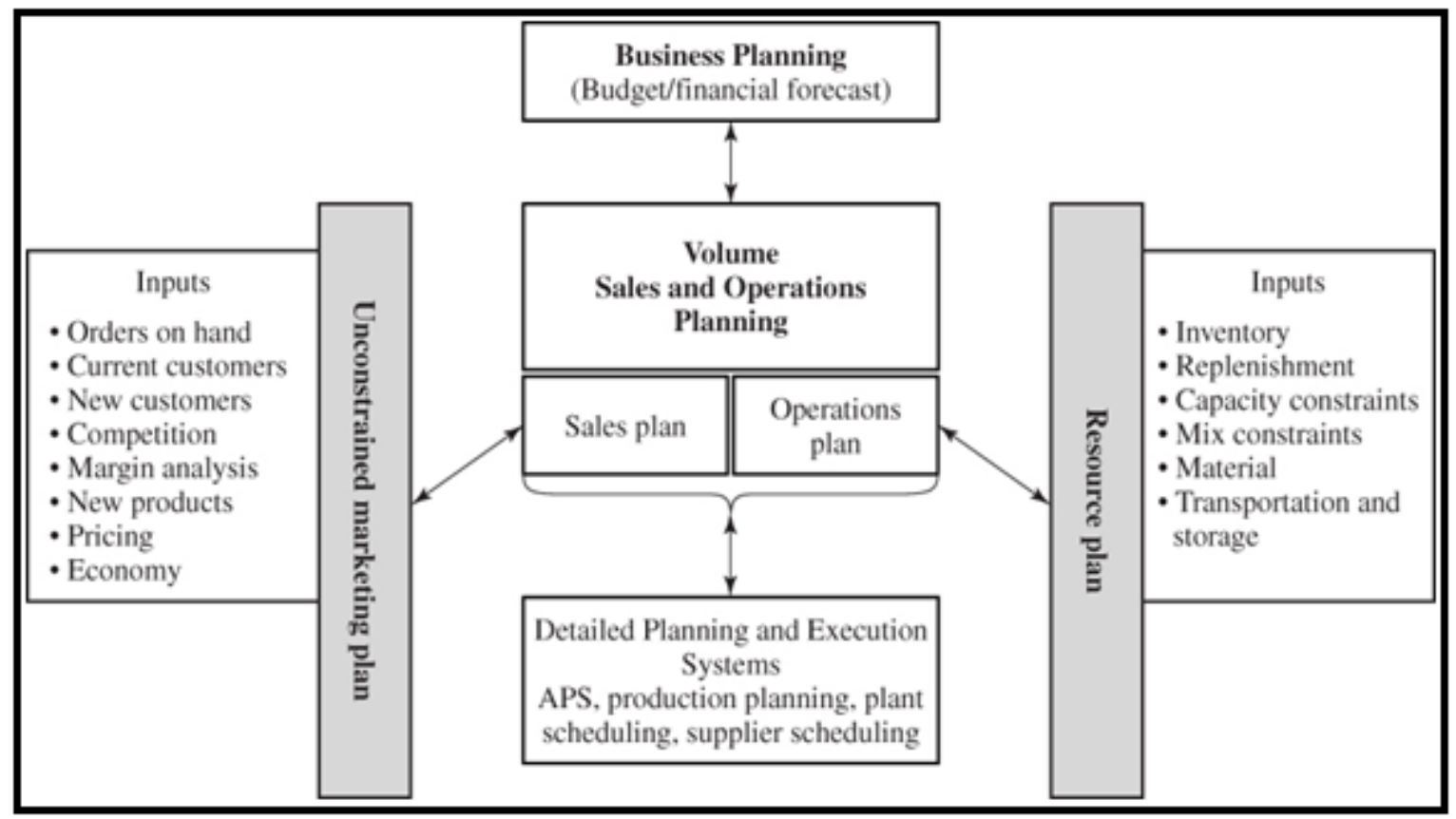

son and Pyke, 2007; Lapide, 2002).

\section{Figure 1. S\&OP Process (Bowersox and Closs, 2006)}

As a second grade; method, upward forecast express new precaution if there is a need after team member's feedbacks are taken. In this process, when enterprise cannot satisfy the demand, new plan will be made that is supported by whole members and additional actions are resolved to increase sales demand. S\&OP also refines supply and demand planning. This is a process, which is consensual planning of supply \& demand, requires stability and collective culpability. S\&OP sales plan includes production and inventory planning, customer delivery time planning and strategically investment and finance planning (Palmatier, 2009). S\&OP process provides effective supply chain management (Bowersox, 2006).

\section{DEMAND FORECASTING SOFTWARE AND ERP SYSTEMS INTEGRATION}

In order to prepare forecasts rapidly and quickly, the demand forecasting software is used. A beneficent forecasting software is supposed to develop forecast recommendations statistically, be integrated with systems maimed to data analysis like Marketing Intelligence, catch the variety in the past dates, be able to filter any sudden demand imbalance and give opportunity to revise it, recognize the any deviation in short-term trends, compare the results lighting with forecasting, suggest optimum stock amount by relating targets of customer service levels and forecasts depending the variety in demand, give simulation opportunity for different forecasts and stock investments.

Looking at forecasting systems; SAP (\%24) is the market leader, and he is followed by Manugistics (\%18), Demand Solutions (\%11), Oracle/People/JD Edwards (\%9), Cognos (\%6) and others(Jain, 2006). While SAP release different modules, with demand forecasting APO (Advanced Planning and Optimization) render service to customers with APS (Advanced Planning and Scheduling) forward planning and optimization module. Besides this module, in SAP, S\&OP works are also supported and used intensely (SAP S\&OP 3.0, powered by SAP HANA) (SAP, 2014). It is seen that innovative solutions in many areas like choosing forecasting models and identification of new models take place in SAP applications. 


\section{CASE STUDY: ANALYSIS AND RECLAMATION OF DEMAND FORECAST STRUCTURE IN XYZ COMPANY}

Forecast is made to decrease the risk at the decision process, while taking decision about future. Uncertainty and related risk is one of the most important factors for director of company. In addition, effect of forecast deviation on operational activity means decrease in the service level or extra stock for the inventory.

$\mathrm{XYZ}$ Company is a pioneer paint producer firm in Turkey. That provides service convenience for the world standards. In Turkey, looking into the tonnage and turnover weighting, it is the leader in domestic area with its modern plant that has the highest capacity among its field. At the same time, the firm has also regional joint ventures abroad. TRNC, Russian Federation, Azerbaijan and Georgia are the basic exportation markets.

The firm employs 1200 employers on the brink of 800 blue-collar and 400 white-collar employers. In its highest capacity plants in its field with 3 shifts capacity, it produces 120 tons of paint.

In the company's plants, it has the highest capacity for the machinery and equipment, and it has five different production groups that produce 6.000 different products. It does not only produce water based paint, furniture paint, solvent group industry paint and agglutinant, but also imports 1.500 diversified commercial product in the direction of market demand. $\% 55$ of raw material necessary for production consists of import materials and the rest of them are obtained by local supplier.

Client groups of XYZ firm are classified as an iron monger style small scale enterprises, corporate clients, retailers, project and export clients. During delivery, external sources are used. Product's area storages are used that is assigned for iron monger clients. For the work site and project, direct delivery is used. For the export products door to door delivery arrangement is made.

\section{The demand forecast system of XYZ company and operational planning effects}

$\mathrm{XYZ}$ Company is trying to estimate the demand by using the classical time series method. Classical time series methods are based on the assumption that considering the data in the past, the trend in the past will continue the same in the future. As a result of the outcome of the analysis, it is observed that the accuracy rate of the demand forecast is $\% 55$. In the industry which is much affected by seasonal demand fluctuations, especially in the summer months when the construction and housing projects accelerate due with increased demand, in the demand forecasting system, taking only historical data and the effects that may occur in some periods of the campaign into account is observed to be another complicating factor for the business to make prediction close to accuracy. The accuracy of the estimate and cost of the effects of the XYZ Company with annual sales of 120 million, the average monthly stock amounts to 20 million, the accuracy of the estimate $55 \%$ are shown in the table below.

\section{Table 1. The Accuracy of the Estimate and the Cost Impact in XYZ Company}

\begin{tabular}{|c|c|c|c|}
\hline & Scenario I & Scenario II & Scenario III \\
\hline Costs (TL) & $\begin{array}{r}\text { The effect of estimate } \\
\text { accuracy } \\
\% 55\end{array}$ & $\begin{array}{r}\text { The effect of estimate } \\
\text { accuracy } \\
\% 60\end{array}$ & $\begin{array}{r}\text { The effect of estimate } \\
\text { accuracy } \\
\% 72\end{array}$ \\
\hline Back Order & 10.660 & 9.600 & 7.467 \\
\hline Sum of the stock & 4.000 .000 & 3.200 .000 & 1.800 .000 \\
\hline The cost of distructedproduct & 180.000 & 162.000 & 126.000 \\
\hline Static (Obsolete) Stock & 9.600 & 8.640 & 6.720 \\
\hline Inactive (Excess) Stock & 3.840 & 3.456 & 2.688 \\
\hline Laggard Stock & 240.000 & 168.000 & 72.000 \\
\hline Production wastes & 580.000 & 460.000 & 320.000 \\
\hline TOTAL (TL) & 5.024 .100 & 4.011 .696 & 2.334 .875 \\
\hline
\end{tabular}

According to scenario I

Difference (TL)

$-$

1.012.404

2.689.225 
As it can be seen in the chart, the impact of $\% 5$ improvement in the estimates is 1 million TL, the impact of approximately \% 15 improvement is 2.65 million TL. The most important improvement here will be assured in the cost of stock, the cost of destructed products, laggard stock and production wastes.

The main problem of XYZ business firm is demand forecasting and high budget deviations; as a result facing the level of service, cost and inventory problems. Suggested forecasting period is mentioned below and in the new period it is recommended to carry this period out together with S\&OP.

The flow shown in Figure2 explains how the flow of information and estimation of studied business administration and businesses similar in structure should be. When looked roughly, the front view received from sales and market, competences investigation with preset methods of prediction and the available resource and understanding with the other operation units are very critical for a structure that will prevent probable accelerated actions. Econometric model is an econometric theory; if we perceive the econometric life as a product of set of simultaneous equation, then econometric model can be defined as the system or fullest extent of these equations. Due to too much variables affecting the demand and the easy supply of statistical data nowadays, it is observed that using econometric forecasting methods is the most reliable forecasting system for XYZ company business. Within this framework, the necessity of combining the forecast period and S\&OP is emphasized.

The work-flow mentioned in Figure2 tells the forecasting period cycle of the businesses. S\&OP systematic, enabling the planning to be in integrated way, tries to generate the plans all the departments agreed on in all sales and supply chain operations. With this work, revising the long-term plans every month regularly, the decreases of deviations after confirmation of the new plans are foreseen. S\&OP is the planning area underlying the strategic plans of the businesses. A proper applied S\&OP period enables to obtain potential benefit by upgrading the business. The companies will obtain very important benefits if they can improve and apply this period every month with discipline. Among the primary benefits, the coordinately working of the sales and operation department and moving towards the common target with common decisions can be said (Stadtler, 2008).

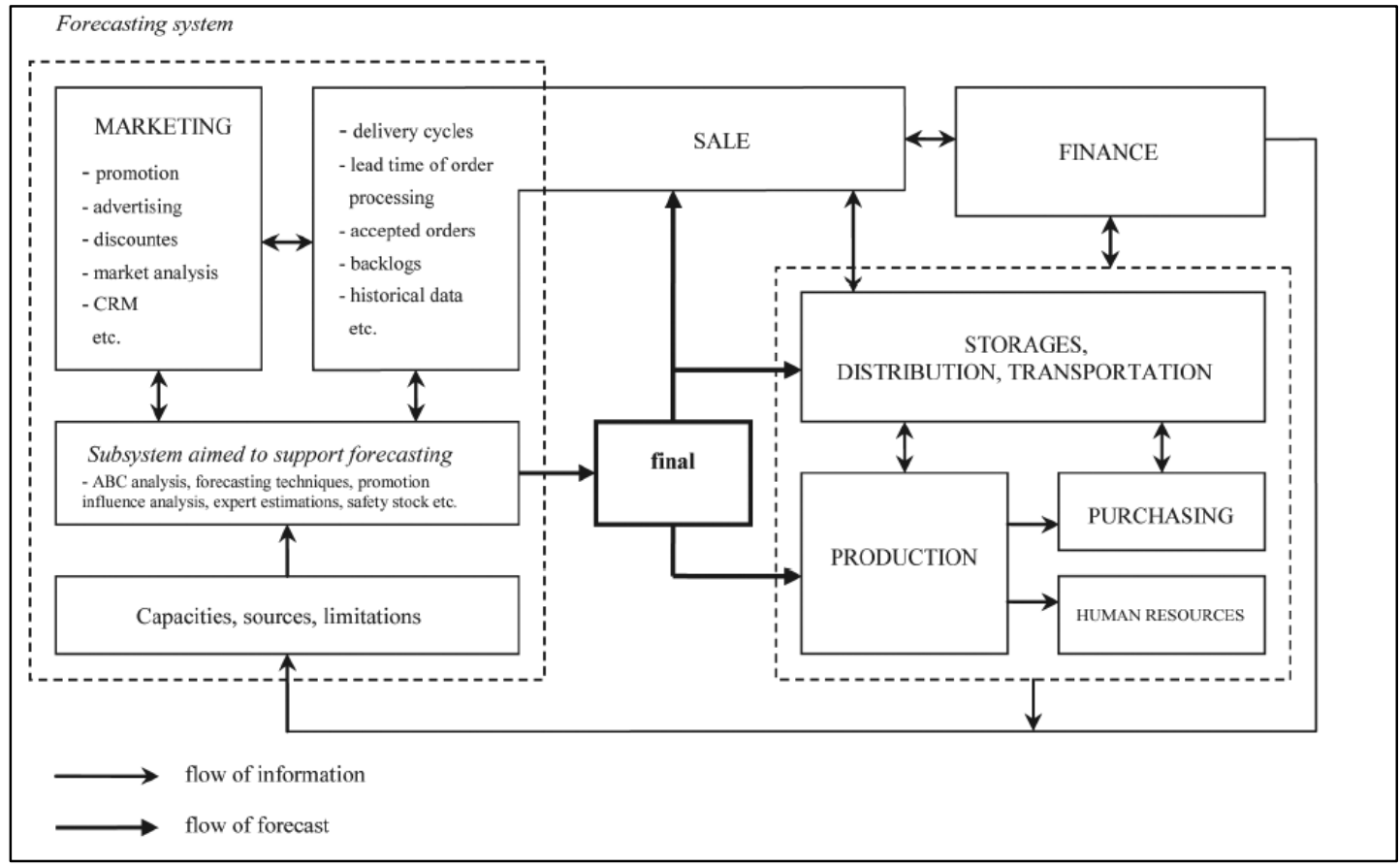

Figure 2. Forecasting Schema (Stadtler, 2008) 


\section{The development of the XYZ Company's demand forecasting system}

After the existing situation analysis, the company's solving problems in the forecasting and increasing forecasting performance will only be available by a new working plan. With this study, we aim to improve the problematic forecasting period by means of the new period.

The method chosen by the company according to their own private conditions can be improved. With this study, generating innovative, plain and improvable solutions are recommended in order to improve the forecasting method and performance. Besides, it is possible to say that only looking constantly for new solutions to make more accurate forecasts and improvements are not adequate itself. Besides these studies, planning these entire organize in the way that can be understood by everyone and specifying the process steps of the organization and the dates to put in use are required.

While we explain the dates of the specified works within the month for the whole processes in Figure2, we specify the relationship with forecast and other operations by S\&OP in Figure3 by recent studies.

As the enterprises are carrying out its activities in an intense competitive environment, the managers encounter ambiguity and risks related to this ambiguity in deciding. While taking decisions about the future, forecasts are being done in order to decrease the risk in the decision period. The more the forecasts are accurate, the more the decisions are reliable. The increase accuracy in forecasting neither can nor is obtained only by statistical and econometrical models themselves. The work should be managed and directed by applications accepted by all in the organization. In the new case, we aim to increase our forecast performance by following up as mentioned in Figure 3.

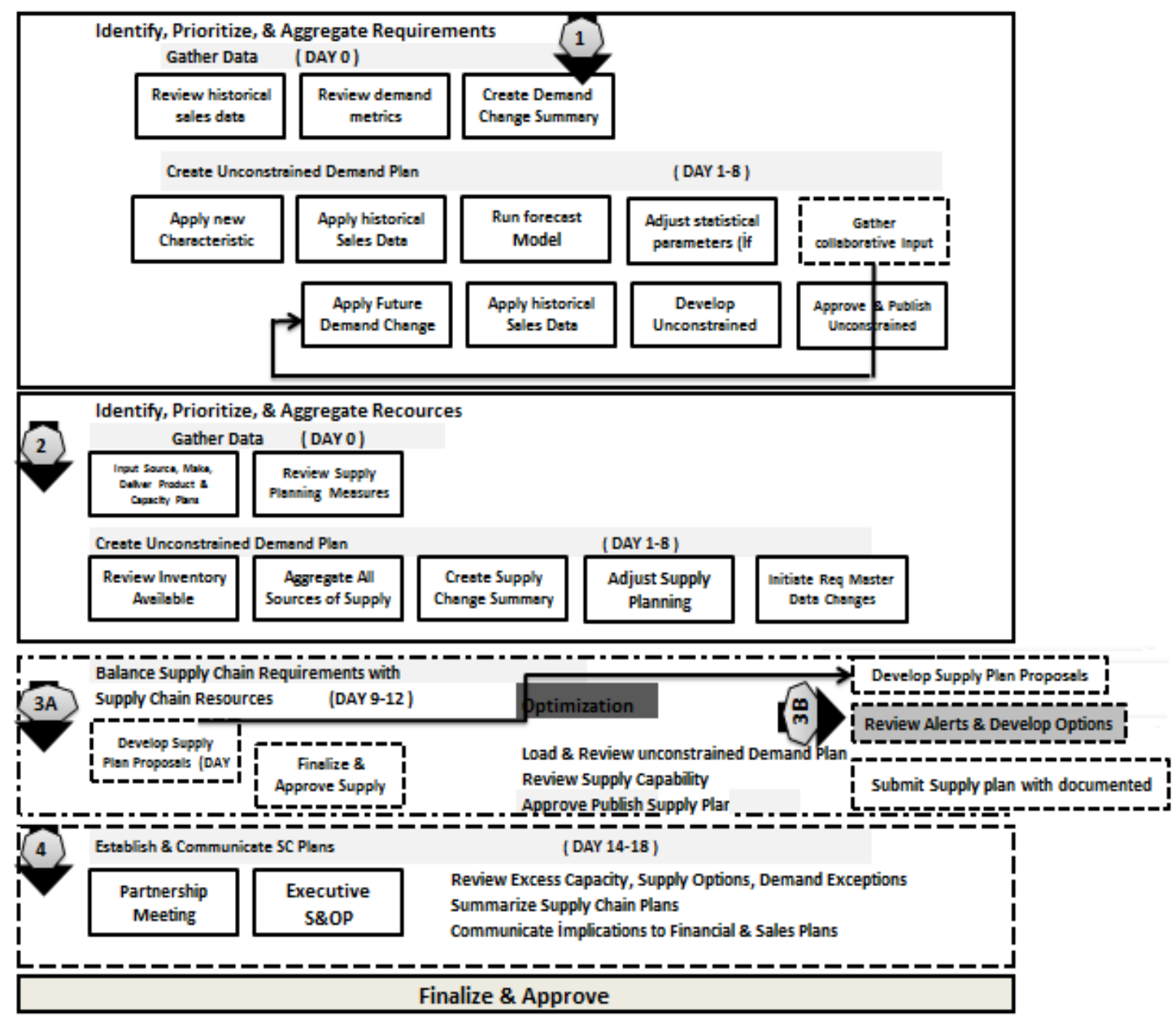

Figure 3. S\&OP Process Steps (adapted from Mentzer and Moon, 2009) 
This working system is planned to go through some process and to be approved by senior participants under the title of S\&OP. Steps are explained below. Primarily, we divided the period into months; we are heading for a structure that will evaluate each month itself and forecast the following month.

1. For S\&OP work, we synchronize the work with specified meeting dates by dividing the present month into working plans. The process steps get started after such notifications as the month that the sales department in, current improvement and the following months; feedback from the market, the current forecasts of the sales managers and specification of campaign dates; and they get their last form with statistical econometric methods determining the demand forecast. Before publishing the last form of the demand plan, the final point to draw attention (if exist) is adding the product which will be exposed to the campaign to the current forecasting model of the current stock condition. Then, the demand plan is published. (1-8 days)

2. According to the current plan, production planning department specify the trademark and product tonnage and publishes the capacity plans. Being created, data such as the workforce needed for meeting current demand and overtime can be mentioned in the capacity reports.

3. Works such as controlling the supply plans and making the material adequacy plans according to the composed production plans and if needed, extra accelerated material supply can be linked to the action. In this step, the point to consider is that if there are supply constraints in the raw material of the products that will be exposed to the impact of the campaign with current capacity, options like delaying the campaign or making campaign for another product, that is product without raw material supply constraints is not the campaign should be worked on. (9-12 days)

4. After the creation of the sales data, picking the production and the capacity plans, the controlling supply plans, all circles of the chain makes their meeting and the manager who is the same level as general director carry out S\&OP meeting. In this meeting, all the constraints are revised and resolved. In short, the dates of the new campaigns are specified, the resolution how long ago the manufacturing business will be stocked is resolved, the supply chain obtain the needed materials, finance take the necessary measures and the most important one is that a decision that all of the organization agrees on is concluded.

Correlating to the mentioned dates is extremely critical for the reliability of the period and for the department that will take role next. Even if there occur problems in the beginning, by this work going through motions there will rise a successful forecast and what is important that a work preventing the accelerated actions.

\section{CONCLUSION AND EVALUATION}

Correspondingly with the technological development, the importance of the demand forecast has been increasing day by day for the enterprises. Nowadays, the forecasting period which was being managed with irrational techniques in the past has been extremely critical work tracing to structures like forecasting manager (director). Along with markets' becoming more dynamic, managers' understanding the importance of forecasting has caused to changes in organizational structure, business philosophy, and corporation culture and has increased the support of the executives to this function. As a result of these developments, the significance of the transparency and cooperation has increased and many concepts and structures such as updating have been come up.

In this paper, the activities oriented to demand forecast of the firms in the paint sector, the increase of the operational productivity, working in cooperation with close relationship and constant circle of the sales and supply departments are designated.

Demand forecasting is a "period". And in this paper, the demand forecasting is discussed as a period and it is understood that a process-based model as "An Econometric Model in Demand Forecasting Period" should be improved and applied in XYZ Company. High forecast accuracy and in parallel with this, improving more accurate market strategy, increase in the stock turnover, decrease in the supply chain costs and increase in the customer satisfaction are described as the output of the period. The reformed economic models can but used as simulation tools in decision support systems. In the policy and strategy that will be developed in short, mid and late phase, one can use these relations. Demand forecasting is not only a function of the marketing. The factors affecting the forecasting accuracy can be grouped as technical difficulties, behavioral problems and 
organizational impediments. In order to carry out the period smoothly, the union of all the participants inside and outside the firm should be ensured and the support of the executives should be taken. In this process, the S\&OP and similar methods should be used. Besides, taking a co-decision and understanding the new decisions, strategies and targets to be developed in high level, standard statistical approaches; increasing the accuracy of the forecasts can be available with S\&OP style application. Cooperation with the customer, smoothening of the demand, proactive cooperation approaches that put together a bilateral relation network between the supplier and customers take place among S\&OP works.

It is necessary to watch out three criteria in order to reach the needed demand forecast results: "accurate and sufficient data, appropriate model and correct assumption". The most important role while providing these criteria lights to the people carrying out the demand period. Demand forecasting is a "period". Seeing it as only a sub-period of the marketing function will make it difficult for forecasting to be adopted by the entire corporation. Out of the possible negative results only the people making the forecast will be responsible, the others will not feel themselves responsible. In order to carry out works about the period successfully, the activities about the period should be carried out as a period; owner of the period, customer of the period, activities in the period and performance indicators of the period should be described. The performance indicators of the period should be followed up constantly and the whole period should be viewed regularly.

In technical literature, using econometric methods in demand forecasting works is mentioned as timeconsuming and costly. This paper shows that approaching to databases has become easier depending on the developing computer technology and increasing use of internet and those econometric models can be used in demand forecasting of the paint sector.

Model is not only used in paint sector, it is but also used in different sectors. While making prediction about future, basic forecast acquired by econometric models, can reflect possible event's effect. As an example, legal changes (reforms), implementation oriented by authorization process, changes on social insurance systems, oversea trends, budget limits (saving limits for specific period) and delay with putting productions on the market (authorization) can be given. Each event can be rendered quantitative method by using incidence date, possibility and effect percentage on basic sales forecast and its effects on period parameters.

Nowadays, it is seen that forecasting models are analyzed much faster with S\&OP style application software systems and that especially the study we mentioned can be used with software systems. As an example, in SAP side forecasting systems and installing different module for S\&OP shows that our studies can be made systematically, faster and easier also on the mentioned software systems of mentioned studies.

A first obvious question is how to model seasonality. This has long been a major research topic that has significant practical implications. Many macro-economic factors are followed by trimester. New model planning can be made to cover these trimesters.

Depending on accuracy of forecast, new studies can be made oriented by stock optimization. When this studies which refer to type of Changeable Demand used with ERP software, on inventory management could be a new start point for practicing about seller stock application (Vendor Managed Inventory: VMI) subject. 


\section{REFERENCES}

Armstrong, J.S. (1988), Research needs in forecasting, International Journal of Forecasting, 4(3): 449-465.

Armstrong, J.S., Morwitz, V.G. and Kumar, V. (2000), Sales forecasts for existing consumer products and services: Do purchase intentions contribute to accuracy?, International Journal of Forecasting, 16:383-397.

Armstrong, J.S. (2001), Should we redesign forecasting competitions?, International Journal of Forecasting, 17(1): 542-545.

Bowersox D. J. and Closs, D.J. (1996), Logistical Management: The Integrated Supply Chain Process, McGraw Hill, USA.

Colin, D.L. (1997), Demand Forecasting and Inventory Control, John Wiley\&Sons, USA.

Erkan, H. (2008), Talep tahmin doğruluğunu arttırmak için talebi etkileyen faktörlerin analizi ve ilaç sektöründe ekonometrik bir model önerisi (The analysis of factors influencing demand with the goal of increasing sales forecast accuracy and econometric modeling recommendations in the pharmaceutical sector), Marmara Üniversitesi, SBE Öneri Dergisi, 3: 24-71.

Fildes, R. and Beard, C. (1992), Forecasting systems for production and inventory control, International Journal of Operations and Production Management, 12: 4-27.

Fildes $R$. and Hastings $R$. (1994), The organization and improvement of market forecasting, Journal of the Operational Research Society, 45: 1-16.

Fildes, R. and Ord, J.K. (2006), Forecasting competitions: Their role in improving forecasting practice and research, in Clements M. and Hendry D. (Eds.), A Companion to Economic Forecasting, Oxford, Blackwell, 322-353.

Gardner, E.S.Jr. and Diaz-Saiz, J. (2002), Seasonal adjustment of inventory demand series: A case study, International Journal of Forecasting, 18(1): 117-123.

Gardner, E.S.Jr., Elizabeth. A. and Angela, M.W. (2001), Further results on focus forecasting vs. exponential smoothing, International Journal of Forecasting, 17(2): 287-293.

Granger, C.W.J. (1989), Forecasting in Business and Economics (2 ${ }^{\text {nd }}$ Ed.), Academic Press, USA.

Grimson, J.A. and Pyke, D.F. (2007), Sales and operations planning: An exploratory study and framework, The International Journal of Logistics Management, 18: 322-346.

Haines, S. (2008), The Product Manager's Desk Reference, McGraw-Hill Professional, NY, USA.

Jain, C.L. (2006), Benchmarking, forecasting, software and systems, Journal of Business Forecasting, 25(4): $28-30$.

Johnson, R., (2009), Sales planning during an economic crisis, Supply House Times, 52(5): 86-90.

Kayhan, M., Erkip, N. and Güllü, R. (2005), Integrating forecast evolution with production-inventory planning: An implementation framework for a fast moving consumer goods manufacturer, Technical Report, Industrial Engineering Department, Middle East Technical University, Ankara.

Kerkkanen, A., Korpela, J. and Huiskonen, J. (2009), Demand forecasting errors in industrial context: Measurement and impacts, International Journal of Production Economics, 118(1):43-48.

Klassen, R.D. and Flores, B.E. (2001), Forecasting practices of Canadian firms: Survey results and comparisons, International Journal of Production Economics, 70(2): 163-174.

Kress G.J. and Snyder. L. (1994), Forecasting and Market Analysis Techniques, Quorum Books, USA.

Lapide, L, (2002), New developments in business forecasting, The Journal of Business Forecasting Methods and Sytems, 21(2): 11-14.

Maltz, E. and Srivastava, R.K. (1997), Managing retailer-supplier partnerships with EDI: Evaluation and implementation, Long Range Planning, 30(6): 862-876. 
Makridakis, S., Wheelright, C.S. and Hydman, R.J. (1998), Forecasting Methods and Applications, John Wiley and Sons Inc, USA.

Mentzer, J.T. and Moon, M.A., (2009), Sales forecasting management: Understanding demand, Supply Chain Management Review, www.scmr.com/scm/article/CA629924.html, [Access Date: April 2014]

Monks, J.G. (1987), Operations Management ( $3^{\text {rd }}$ Ed.), McGraw-Hill Int. Ed., Singapore.

Render, B. and Stair, M.S. (2000), Quantitative Analysis for Management (7th Ed.), Prentice-Hall Inc., USA.

Stevenson, W. J. (1989), Introduction to Management Science, Irwin Inc, USA.

Palmatier, G. (2009), Sales \& Operations Planning (integrated business management): An executive level synopsis, Oliver Wight White Papers Series.

Sanders, N.R. and Ritzman, L.P. (1992), The need for contextual and technical knowledge in judgmental forecasting, Journal of Behavioral Decision Making, 5:39-52.

Sanders, N. and Manrodt, K.B. (2003), Forecasting software in practice: Use, satisfaction, and performance, Interfaces, 33(5): 90-93.

SAP (2014), https://help.sap.com/sop [Access Date: January 2014]

Sheldon, D.H. (2006), World Class Sales and Operations Planning: A Guide to Successful Implementation and Robust Execution, J. Ross Publishing, Lauderdale.

Schroeder, G.J. and Snyder, J. (1994), Forecasting and Market Analysis Techniques: A Practical Approach, Quorum Books, USA.

Stadtler, H. (2008), Supply Chain Management and Advanced Planning: Concepts, Models, Software, and Case Studies (4 ${ }^{\text {th }}$ Ed.), Springer, Berlin, Germany.

Wacker, J.G. and Lummus, R.R. (2002), Sales forecasting for strategic resource planning, International Journal of Operations and Production Management, 22(9):1014-1031.

Wilson, J.H. and Keating B. (2001), Business Forecasting (4 ${ }^{\text {th }}$ Ed.), John Galt Solutions, USA.

Winklhofer, H., Diamantopoulos, A. and Witt, S. F. (1996), Forecasting practice: A review of the empirical literature and an agenda for future research, International Journal of Forecasting, 12:193-221.

Zoghby, J. (2002), Lessons learned from implementing forecasting and planning systems, The Journal of Business Forecasting Methods and Systems, 21(1): 17-19. 